\title{
CliENT-BASED CORNERSTONE DESIGN PROJECTS
}

\author{
Justine Boudreau, Hanan Anis \\ University of Ottawa \\ jboud030@uottawa.ca; hanis@uottawa.ca
}

\begin{abstract}
Engineering students at the University of Ottawa are exposed to engineering design in first- and second-year courses. Both courses are open to all engineering students and are multidisciplinary in nature. Students work in teams to deliver a physical prototype by the end of the term. The design projects are all community-based and involve a client from the local community with a specific unmet need. Examples of such clients include local hospitals, accessibility organizations, Ottawa police, Indigenous elders and many more. The client meets with the students a minimum of three times throughout the semester to provide the problem definition and give feedback to the student groups at different stages of the design process. The goal of this paper is to share best practices in selecting and delivering client-based projects targeting first- and second-year students in multidisciplinary engineering teams. The paper discusses the choice of project themes and specific projects. In addition, it presents lessons learned based on studentclient interactions, lab manager-client interactions and client satisfaction. Examples are presented from the past three years of delivering such engineering design courses, with testimonials from clients and students.
\end{abstract}

Keywords: Makerspaces, Client Based Design, Cornerstone Design Curriculum, Project Based Learning.

\section{INTRODUCTION}

Project-based learning combines the typical engineering theory subjects with hands-on building and prototyping [1], [2]. Benefits of experiential learning include increasing understanding, knowledge application and integration [3]. These projects also have the goal of promoting teamwork, design thinking and creativity by combining the theoretical and practical [4].

Multidisciplinary groups are important since students will find themselves working in teams with all types of people when they enter the workforce [5]. Different skill sets and ways of interpreting information and experiences are particularly important for solving complex problems like those presented by an engineering design project [5], [6].

"[C]lient-based projects can serve as a bridge between the academic and workplace worlds." [5, p. 132] For many universities, project-based learning has evolved to incorporate industry in academics via client-based projects [3], [7]. The projects benefit the students as well as the client. In addition, project-based learning promotes university and community collaborations [1].

Client-based projects are typically done in capstone projects [2], [3]. Partnering with industry is less risky in this case because the students are more mature, have more knowledge and have a better chance of success in their project. However, as Zsidisin, Hartley and Collins point out, if these projects are not properly managed, "students and clients will be dissatisfied." [3, p. 390] There are many challenges with client-based projects, including finding a client willing to participate and share, identifying an appropriate scope and fitting the project into the learning objectives of the course [3]. These challenges are compounded in cornerstone design courses because the abilities and knowledge of the students can be limited. Nevertheless, it is important to introduce students early to client-based projects. Such projects help students develop technical, communication and people skills [5], [6]. Moreover, they provide students with a deeper understanding of the context of the potential impact on society of such work. They also allow students to experience real-life scenarios, and they provide tangible motivation [5], [6].

To address these challenges, we believe communitybased projects are ideal for first- and second-year engineering design courses. The clients' expectations are not set extremely high, and they are prepared to work with the students over a number of semesters before possibly getting a functional product. These projects are also used 
to address a specific individual or organizational need rather than required to be at a quality needed for industry.

In this paper, we discuss the best practices and lessons learned from two cornerstone project-based design courses. These courses were developed in 2015-2016 as a part of the NSERC Chair in Entrepreneurial Engineering Design at the University of Ottawa. Both courses centre on interaction with community clients and multidisciplinary engineering teams.

Many client-based projects in engineering design are done in capstone design courses; however, faculty research and industry still dominate the source of projects. Some universities are moving towards cornerstone design courses. Rice University introduced a client-based multidisciplinary project design course in 2011 that greatly resembles the one described here, with prototypes being made for external clients, and that is similarly successful [9]. In addition, Memorial University includes meaningful assistive-device projects in its first-year engineering design course to motivate students in their projects and contribute to a client's personal life [10]. Ohio State University's senior design course and Louisiana State University's freshman design course also highlight the successes and benefits of client-based projects for both levels of courses for students, instructors and clients [7].

\section{PROJECT-BASED LEARNING APPROACH}

\subsection{Courses}

The University of Ottawa offers a first- and a secondyear engineering design course. The second-year course accept students from all engineering departments and from all years. The students work in teams of four to six to deliver a physical prototype by the end of the term with a budget of $\$ 100$. The prototype is built to solve a need of a community-based client recruited for either course. All teams meet with their clients a minimum of three times throughout the semester to gather information and receive feedback on their designs. At the end of each semester, teams also showcase their project at Design Day, which the clients are invited to attend.

In the first-year course, Engineering Design, all groups from the same class section work on the same project. Their client first presents the problem to the entire class, then meets each group individually when they have conceptual designs in their lab, and then finally listens to a formal presentation in class from each group based on their prototype.

The second-year course, Introduction to Product Development and Management for Engineers and Computer Scientists, has multiple projects so that a maximum of two groups work on the same project in the same term. Teams choose their top three choices of projects, and professors distribute them according to choice and meeting restrictions. The groups meet their client one-on-one three times: first to gain a better understanding of the problem, second to get feedback on conceptual designs and third for feedback on the prototype.

The theme for the first-year course changes almost every semester and is different between sections. The theme for the second-year course is always accessibility. This means students work on projects like wheelchair skis, portable wheelchair ramps and foot-controlled guitars. Clients are diverse, ranging from individuals to organizations like hospitals, and all have different needs.

Both courses have one teaching assistant (TA), who is a graduate student, and a project manager (PM), typically a senior undergraduate student who has taken the course previously. They act as guides and mentors to the groups as they go through their design process and learn the skills necessary to complete their projects.

\subsection{Optimal Clients}

Clients and projects must be chosen carefully because they are tied to grades and to available materials and facilities. Making the right choice has an enormous effect on the success of a semester for students and staff. Criteria to consider for clients are availability, motivation, location and language.

First, since clients are required to meet multiple times, their schedules must be flexible enough to allow them to make these meetings. They must also agree to a time commitment of a minimum of four-and-a-half hours (three meetings of one-and-half hours). The first-year course has stricter scheduling requirements because the client attends two lectures and multiple lab sessions during the semester. Because of the large number of groups working with a single client, rescheduling these outside of official class times would be next to impossible. Therefore, the clients must be present during these specific meeting times, which are often during the day. The meetings for the second-year course happen 
during the lab times, so it is ideal if clients are available during their team's lab time. However, many of these meetings tend to get rescheduled, since some clients cannot leave work during the day. This doesn't usually pose a problem, because meetings with only one or two student groups are easier to reschedule.

Second, the best clients are the ones who are extremely motivated to solve the problem presented. This means they are willing to answer questions from the students throughout the semester by providing their contact information directly to the teams and making themselves available for the meetings. In addition, they will offer resources at their disposal to engaged teams looking to perfect their solution. For some clients, motivation comes from the possibility of getting a device that would greatly help them as part of their job or as part of their daily life, and for some their community would gain from the project. For example, many of the accessibility projects are done for specific individuals to help them in their life, while the virtual reality project to help cancer patients feel better during radiology or chemotherapy procedures is done to help that community of people.

Third, the clients need to be based in Ottawa (or in the near surrounding region). In the first-year course, this makes it easier for clients to attend the on-campus meetings. For the second-year course, students must be able to travel to the client's location, have the meeting and return to campus within their three-hour lab session.

Finally, the University of Ottawa is a bilingual university, and so these courses are offered in French and English. The clients must speak one of these languages and are placed in the right section to communicate with the students who, in many cases, can understand only one of the languages.

The courses have had two main types of clients: individuals and organizations. In the first-year course, there is not much difference between an individual and an organization since one to two people will typically be present on behalf of an organization and have the same meeting requirements as any other client. The second-year course has clients from different types of organizations, such as accessibility organizations, special needs programs and hospitals. In those cases, a facilitator who is familiar with the project will supervise meetings and help the groups understand the problems. Organizations will often provide multiple projects with multiple clients, making organizations ideal for the second-year course, which needs many different projects.

\subsection{Interacting with the Client}

2.3.1. Student interaction. Each student group meets with their client a minimum of three times in the semester, either one-on-one with their team or in a large group setting in the classroom.

(a) First client meeting: The first meeting takes place in the third week of the semester. In preparation for the meeting, students in both courses learn about needs identification and about problem definition and refinement in lectures. They learn the importance of empathy and how to ask questions that encourage clients to tell stories and share pertinent information about their problem. The students are taught the importance of keeping an open mind to identify needs and requirements from information gathered from the client. The groups are then tasked with making an interview protocol (or coming up with open-ended questions). They are also taught that each of them will have a different role during the interview/meeting: some should be the ones asking questions, while others should take notes to record all information (verbal and non-verbal) provided by the client. The first-year course hosts the first meeting in a class where the client gives a presentation to all students about the background of the project with basic requirements for the products to be built. The students then have the chance to ask their questions as a big group and learn from each other. The students from the secondyear course meet alone with their client and TA or PM. The client has the opportunity to explain their problem, express why it is important to them specifically and describe what particular requirements they may have due to their disability or the disability of the community they are representing. Moreover, the students often get the opportunity to observe the client experiencing the problem and to develop an understanding of the environment in which the client will be using the product. As with the first-year course, the students then ask their prepared questions.

(b) Second client meeting: The meeting takes place in the fifth or sixth week of the term. It is preceded by lectures on design criteria, ideation and design analysis. The groups learn to transform their recorded client needs into design criteria and specifications. These are then used to develop their conceptual designs and choose the best one. They present one or more concepts to their client during the second meeting to get feedback on different parts of it, like general functionality, size, appearance, etc. 
This process helps them make decisions moving forward with the concept to build their first prototype in the following weeks. The meetings happen one-on-one with the team and the client for both courses, with supervision by the TA or PM. This gives the client the chance to focus on each group individually for a set amount of time and explain the reasoning behind their likes and dislikes of the concepts.

(c) Third client meeting: Teams present a first physical prototype to the client during the meeting. This is a zerodollar prototype meant to illustrate the basic functionality and geometry of the product and to elaborate on the ideas of the concept drawings. The students learn about prototyping and testing plans to adequately analyze their solutions and measure their success. The client provides feedback on this first prototype to guide the groups towards a solution that is suitable for their needs. This meeting in the first-year course takes place in week eight, during a lecture as in the first meeting. Each group is required to make a formal presentation to the class while the client is present, followed by a few minutes for questions and feedback by the class and the client. It is useful for the client to hear the progress of each group and be able to comment on what teams have created so far, as well as for the teams to know how they are doing in comparison with the other teams. This helps to motivate them and gives them an opportunity to practise their presentations skills for the showcase and their final presentation at the end of the semester. For the secondyear course, the third meeting happens in the seventh week of the semester. Like the other two meetings for the second-year course, the third happens with the same people present in order for the client to give opinions on the prototype.

Following the three meetings, each team develops at least two more prototypes and can contact the clients for feedback in most cases in-between the last meeting and the final Design Day showcase.

2.3.2. Manager interaction. A lab manager for these courses has been appointed to be the point of contact between the clients and the course, to schedule meetings and organize all labs. It is also the lab manager's job to look for new projects for each semester and ensure they are suitable for these specific courses, all of which takes a considerable amount of time.

Clients can be individuals or come from various places, including industry and non-profit organizations.
They are found through personal connections, word of mouth, open house initiatives, etc. While the clients are being recruited, the meeting frequency, time commitment and product expectations are all made clear to them. The clients must know what is needed from them in terms of basic requirements for the course (minimum of four meetings) to ensure they are able to take part and interested in going on this journey with the students. It is also important to give them the option of more or less contact with the students outside of the set meetings to adapt to their prior commitments (the first-year course with 72 students in a section will have different demands than one project of five students in the second-year course). The last piece of important information that is communicated to the clients to keep in mind is that the course has a heavy workload, which means the final results will vary based on the group of students working on the project. Just as a distribution of grades is normal in a course, so too will there be a range in the quality of products produced. In the case of the first-year course with up to 15 teams working on the same project, chances are much higher of getting one or a few excellent quality products that can be directly used or easily modified to reach the next level. However, clients in the second-year course who work with only one team may not end up with a motivated group that delivers a functional prototype. In each case, expectations must be set in terms of what firstand second-year students are able to produce over the course of one semester with a limited budget and, realistically, not an extensive knowledge base to begin with.

When clients are selected to be part of the course (and their projects are assigned to individual groups, in the case of the second-year course), the lab manager will explain the process for the first meeting, which depend on the course the client will be participating in. Clients are told to give background information about themselves, provide the motivation for their project and describe what their problem or project is. They must also provide information about restrictions that would give a scope to the project. However, the clients are instructed not to give any particular suggestions for solutions or technologies to use. Instead, they are asked to explain past solutions they may have tried or seen and what they liked and disliked about them. The reason for this is to not restrict the imagination of the students when they are doing their conceptual designs. 
The second meeting involves less preparation on the clients' part; they are providing feedback to the students based on what the students show them at the meeting. This is a feedback meeting on the conceptual designs, so clients are told to expect hand drawings or possibly 3D models to represent the result of the team brainstorm. The clients must then give their opinion based on what features they are looking for in terms of functionality and their various other needs so the teams can iterate and come up with their first prototype.

The third meeting is similar, the difference being the feedback is now based on the first prototype. This prototype is made of low-cost materials to represent the concept or a critical subsystem of the concept for the clients to get a better idea of the interaction between the parts and global features. Again, the clients are told what to expect and asked to give feedback on anything they can think of to help get the solution closer to what they are looking for.

\subsection{Client-Based Themes and Projects}

To ensure that the semester is a success, projects must also be chosen carefully. Both the themes and specific projects are looked into in detail to make sure they are suitable for these design courses.

The theme for the first-year course is different for all sections and tends to change depending on the client found for a semester. However, there have been a few recurring themes with a slightly different projects with a varied goal. Some of these include hydroponics (for cafeterias, schools, etc.) and art integration (installations for a new building, sculptures from recycled materials, etc.). The choice of theme for the second-year course is always accessibility. This theme offers a multitude of different projects and fits the format of the course in which the students meet with a client one-on-one. Accessibility is also a subject that is relatively common for team-based engineering design courses [6]. It allows students to adapt their designs to a specific person or group and listen to their particular needs. It is also a subject that is meaningful and forces the students to reflect on diverse segments of the population when designing a product. There are also many organizations that work with people with disabilities, which makes finding partners and projects easier.

Themes for the first-year course can be varied, as long as the project specifics are good for the course's project- based learning that includes elements of making. Important factors to consider are the type of skills needed to accomplish the project, the complexity of the project, possible technology involved and the approximate cost for critical components. The first element, types of skills, is crucial in terms of what the students are capable of producing at the stage of education they are at. There will be a limit to the kinds of analysis they are able to perform on different parts of their product to validate its effectiveness. It will also have some effect on the concepts they will choose. For example, projects that require more advanced mechanics or complex circuit design are not ideal for first- and second-year students. Second, a project can't be too complex and involve too many parts for a team to be able to complete in one term. Since the students must complete three prototypes in the span of the term with their four to six members, it would be impractical to have a system with more than about three main sub-systems. Third, the resources that the groups have access to for the development and construction of their prototypes is limited to the facilities at their disposal. This includes a makerspace and a machine shop, both of which have various equipment that the students get training for in their labs for the courses. Therefore, projects that would not be doable with only 3D printing, laser cutting, drilling, milling, etc., would also be very difficult to accomplish for the groups. Finally, when choosing a project, the basic research into possible components the students might want to use must result in low-cost alternatives. Open-source technology like Arduino is excellent for finding online help and resources as well as generally having cheap components it can interface with. Since the budgets are fixed at $\$ 100$ for both courses, a project cannot be chosen if it requires a specific component that costs over $\$ 50$, for example.

The University of Ottawa projects vary in nature to offer students a varied and interesting experience. Some projects are purely mechanical (wheelchair accessibility projects, for example) or purely software (virtual reality or app-based accessibility projects), and some are a mix of subjects, such as a full-sized shed with solar power and full automation.

The variety of projects that can be undertaken is vast, and the combination of the right project and client makes for a successful semester with happy clients and students. A great deal of time, mainly by the lab manager, is put into finding these projects and developing relationships with the clients. Funding is also key, since a majority of 
the teams spend their whole budget of $\$ 100$. With over 100 groups, the total can get close to $\$ 10,000$ in one semester spent on materials alone. To lower this cost, at the end of each semester, the projects that were not completed, are not functional and do not have much potential for improvement are disassembled and the parts are reused in future projects. Redoing projects of the same nature also helps in this regard, since popular items can be bought in bulk to lower costs or can be reused from the previous projects.

\section{METHODS}

Clients who had taken part in the courses in the past 2 years were asked to answer a survey about their experience. The survey asked about the professionalism of the students and PM, the interpretation of their needs, the prototype quality and the overall experience; it also provided space for comments. This tool was used to facilitate understanding of the client experience and save the time that would have been needed to do longer interviews.

The survey asked about the level of satisfaction of 5 criteria on a scale of 4 , for a total of 20. (See Appendix A.)

Past students from both courses were also asked to give their views on the course and their experience with the clients. (See Appendix A for the questions.)

\section{RESULTS AND DISCUSSION}

Based on eight clients who answered the survey, the average total satisfaction level was $91 \%$ and the reported experience with the University of Ottawa and its students was good. Here are a few comments from clients from the second-year course:

"I quite enjoyed working with the students. They were polite, respectful, and interesting in developing something which would be useful."

"We sincerely appreciated this opportunity. It was really great having young minds make my son's dream a reality. I shared the process on social media and our friends and family in New York and New Brunswick were very excited to see this come to fruition. It really was a Wow Experience!!! Never say never! I can't stress how awesome this has been to prove to everyone that where there is a will, there can be a way."
The following comments are from an accessibility organization:

"We really loved having your students in our program. I believe that having this opportunity for your students provides them the opportunity for self-advocating. This experience also provides CEED [Centre for Entrepreneurship and Engineering Design] students the valuable opportunity of working with persons with disabilities and see how projects they work on can be inclusive for all."

"Exposing students at an early age to accessibilities issues is already a big achievement that they can carry on through life without really realizing it."

The clients for the first-year course expressed similar feelings:

"It was great working with you!"

"Tes étudiants sont des superstars." [Your students are superstars.]

"I think it was great!"

Over the years, some clients have recommended that ways be found to get more projects to a satisfactory state of completion: "I would like to see a greater rate for completed projects and ready to be tested and eventually used by our clients."

The completion rate is hard to control because the quality of the teams varies. To circumvent this issue, unfinished projects are kept for the following semester for other groups to keep working on. In addition, all of the projects get posted a project-sharing website (makerepo.com), which makes it easy for the next groups to use the knowledge passed on from the first iteration of the project. This also allows the clients to have access to project files and use them as they wish.

Exposing the students to real-world problems is as important to the clients as it is to the University, particularly when accessibility challenges open students' eyes to the different ways some people have to navigate the world.

Face-to-face client interaction is important for the students because it gives them a sense of perspective on the problem and helps them understand the situation their client is facing. They are able to use empathy and interact professionally with the client, which is crucial practice for the workforce. In answers to student interview questions, second-year course students stated:

"The importance of having a real client on our part was significant in directing our solution towards their specific needs. Tailoring the solution [from] an initially 
'ambiguous' problem to a more specific issue with broken down issues..."

"It helps you to connect to the project more."

The subjects chosen also give students the chance to look at problems that different people or communities are dealing with that are not necessarily well known. For example, the struggle of a person in a wheelchair to use a public washroom or the amount of overcrowding in homeless shelters is not something many people are aware of or think about every day.

The students from both courses agree that the clientbased projects give them a sense of purpose and a feeling of making a difference versus doing a project only for marks in a course:

"[The] clients [have] given students a lot more enthusiasm in the project because they feel like they have the potential to actually 'make a difference' in something and produce something that is feasible for use in the real world."

"Having real clients encourages diverse and interesting projects and gives relatively inexperienced students an opportunity to create something that (if successful) may be used in the real world."

"I believe that real clients are important as they allow the students to realize that they're not just doing a project to present to the Prof and get a mark, but rather that their project will live on after they're done, either in the hands of the client, or in future students looking to complete their project."

The students also recognize that they are accountable to the clients and try their best to make a great product for them:

"Knowing that there was an actual client encouraged us to create the most successful product possible."

"[T] he students realize that their product will have a real impact on the world, further encouraging them to strive for excellence."

\section{CONCLUSIONS}

Community partners are particularly suited for cornerstone design projects, as their expectations are lower than those of industry. However, all client-based projects present unique challenges and take a significant time to organize properly. Consequently, it is important to start early and have a person on the team who is responsible for finding clients. Choosing appropriate projects is critical. First, projects themes should be interesting for the students, able to be executed within a semester and at an appropriate level of complexity for the students involved. Second, managing client expectations is critical. Clients should be told that not every project will be successful and that many projects will need more than one term to complete. Third, dealing with clients requires students to behave professionally, and some mentorship is needed. Moreover, setting clear communications protocol is needed so students get answers to their questions in a timely fashion, yet the client does not get overloaded with questions and requests.

Client-based projects are a win-win. Clients are able to solve problems they are experiencing, while students are able to put their knowledge to the test in a hands-on project that meet a real need of a client. Both clients and students agree that it is a great opportunity for collaboration and provides an avenue for positive social change.

In the future, the University of Ottawa would like to work with international clients to expand the subjects covered, work with a greater variety of clients and create further successful experiences.

\section{Acknowledgements}

Without our clients, none of our success would be possible. We thank them infinitely for the time they spend with us. These programs are possible due to the NSERC Chair in Entrepreneurial Engineering Design.

\section{References}

[1] L. E. Carlson and J. F. Sullivan, "Hands-on Engineering: Learning by Doing in the Integrated Teaching and Learning Program," International Journal of Engineering Education, vol. 15 , no. 1 , pp. 20-31, 1999.

[2] M. W. Cooper and K. K. Goodell, "Industry Sponsored Capstone Projects: Factors Influencing Success," in Industrial and Systems Engineering Research Conference, 2014, pp. 1472-1484.

[3] G. A. Zsidisin, J. L. Hartley, and W. A. Collins, "Integrating student projects with real-world problems: the case of managing commodity price risk," Supply Chain Manage.: Int. J., vol. 18, no. 4, pp. 389-397, 2013.

[4] C. L. Dym, A. M. Agogino, O. Eris, D. D. Frey, and L. J. Leifer, "Engineering Design Thinking, Teaching, and Learning," Journal of Engineering Education, vol. 94, no. 1, pp. 103-120, 2005.

[5] P. Wojahn, J. Dyke, L. A. Riley, E. Hensel, and S. C. Brown, "Blurring Boundaries between Technical Communication and Engineering: Challenges of a 
Multidisciplinary, Client-Based Pedagogy," Technical Communication Quarterly, vol. 10, no. 2, pp. 129-148, 2001.

[6] M. R. Goldberg and J. L. Pearlman, "Best practices for team-based assistive technology design courses," Ann. Biomed. Eng., vol. 41, no. 9, pp. 1880-1888, Sep. 2013.

[7] A. D. Christy and M. Lima, "Biological engineering student design projects with real clients," in 1999 ASEE Annual Conference Proceedings, 1999, p. 7p.

[8] C. Vincent and P. Wild, "CURRENT PRACTICES IN FINAL YEAR ENGINEERING DESIGN COURSES," in Proceedings of the Canadian Engineering Education Association (CEEA), Winnipeg, Manitoba, 2011.

[9] A. Saterbak, M. Embree, and M. Oden, "Client-based projects in freshman design," in American Society for Engineering Education (ASEE) Conference Proceedings, San Antonio, 2012.

[10] L. Lye, "Incorporating Real-Life Open-Ended Design Projects In A First Year Design Course," Proceedings of the Canadian Engineering Education Association (CEEA). 2011.

\section{APPENDIX A}

Client survey questions

1. How satisfied were you with the level of professionalism of the students?
2. How satisfied were you with the level of professionalism of the project manager?

3. How satisfied were you with the student interpretation of your problem/project?

4. How satisfied were you with the prototype quality?

5. How was your experience in general?

6. Do you have any suggestions for ways to improve your experience?

7. Would you be open to working with us again?

8. Do you have any other comments you would like to share?

Student interview questions

1. What effect did the client have on your experience in the course?

2. Was it important to have real clients?

3. Would your design process be different without a client? 